\title{
Growth, carcass and meat quality traits of two South African meat rabbit breeds
}

\author{
M.K. North ${ }^{1}$, A. Dalle Zotte ${ }^{2}$ \& L.C. Hoffman ${ }^{1,3 \#}$ \\ ${ }^{1}$ Department of Animal Sciences, Stellenbosch University, Private Bag X1, Matieland, Stellenbosch 7602, South Africa \\ ${ }^{2}$ Department of Animal Medicine, Production and Health, University of Padova, Agripolis, Viale dell'Università, 16, 35020 \\ Legnaro, Padova, Italy \\ ${ }^{3}$ Centre for Nutrition and Food Sciences, Queensland Alliance for Agriculture and Food Innovation (QAAFI), The \\ University of Queensland, Health and Food Sciences Precinct, 39 Kessels Road, Coopers Plains 4108, Australia
}

(Received 20 May 2019; Accepted 10 August 2019; First published online 1 October 2019)

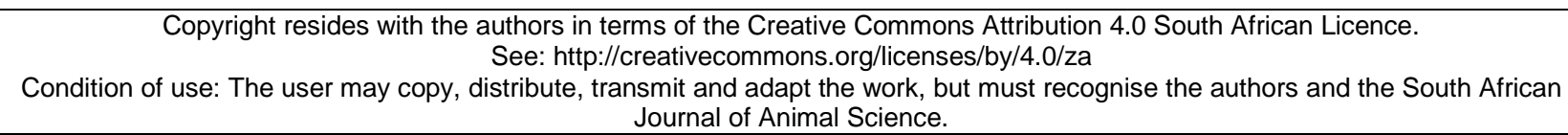
Journal of Animal Science.

\begin{abstract}
Rabbits could contribute to meat production in South Africa. However, little research has been done on rabbit farming in the country, including on the performance of locally available meat breeds. This study examined the meat production of the New Zealand White (NZW) and Phendula rabbit breeds. The live weights (LW) and average daily gains (ADG) of 80 (44 male, 36 female) NZW and 40 (22 male, 18 female) Phendula rabbits, housed in single-sex groups of three, were recorded from weaning (5 weeks) until slaughter (11 weeks). The slaughter weight, and carcass, organ, and carcass portion weights were recorded for 10 male rabbits and 10 females of each breed, and the physical and proximate chemical quality of the loin meat was determined. The breeds differed for the reference carcass (RC) yield (NZW: $85.3 \pm 0.14 \%$; Phendula: $84.9 \pm 0.24 \%$ ) and the proportions of the low-value fore (NZW: $38.6 \pm 0.26 \%$; Phendula: $37.6 \pm$ $0.28 \%$ ) and high-value intermediate (NZW: $19.6 \pm 0.16 \%$; Phendula: $20.4 \pm 0.28 \%$ ) parts. Females had greater LW and ADG at 11 weeks old, and reduced dressing percentages, but greater RC yields owing to lighter heads and red offal. Females also had smaller proportions of the fore part. Meat quality did not differ between the breeds or sexes. Overall, both breeds compared well to previous reports. However, they appeared to mature relatively early, as indicated by the significant sex differences, and the high carcass and meat fat content.
\end{abstract}

Keywords: carcass portions, meat yield, New Zealand White, Phendula

${ }^{\#}$ Corresponding author: louwrens.hoffman@uq.edu.au

\section{Introduction}

Rabbits may have the potential to contribute to both commercial and subsistence meat production in South Africa. They share many of the advantages of poultry, as they can be reared intensively (Szendrő \& Dalle Zotte, 2011), can easily be handled by women and children (Lukefahr, 2007; Abu et al., 2008), and can be slaughtered as required for consumption. In addition, they are highly prolific, grow rapidly, and can be fed a high-fibre low-grain diet, reducing the competition with human beings for feed resources (Finzi, 2000; Abu et al., 2008). An additional advantage is that two serious rabbit viral diseases, namely rabbit haemorrhagic disease and myxomatosis, have never been reported in South Africa (CABI, 2019a, b).

Maintaining the disease-free status of the country has required banning the importation of all rabbits and rabbit material, meaning that for the past 33 years or so the rabbit population of South Africa has been genetically isolated from the rest of the world. Furthermore, despite their potential, rabbits are under-utilized in the country, and research on the local genetic varieties and farming under South African conditions is scarce. Only three studies on the growth and meat quality of South African rabbits have been published in recent years (North et al., 2017; North et al., 2018a,b), in addition to two studies that examined the perceptions of rabbit meat by South African consumers (Hoffman et al., 2004; Hoffman et al., 2005).

The aim of this study was therefore to provide standard growth, carcass and meat quality data for two meat breeds that are available in the country, namely the New Zealand White (NZW) and the Phendula. The NZW is a globally recognised meat breed, and has been an essential contributor to the development of many 
of the hybrid lines used for meat production in other areas of the world (Lebas et al., 1997). In contrast, the Phendula is a local landrace breed that has been developed since 2002, which was recognised officially by the South African Rabbit Judges Council only in 2014. The Phendula was selected with the objective of producing a hardy adaptable breed that is suited to the South African climate, and that incorporated genetics from Chinchilla Giganta, Flemish Giant, New Zealand Red, and New Zealand Black rabbits (recognised breeds in South Africa), as well as those from hardy nondescript rabbits in the area (Gauteng Smallholder, 2014).

\section{Materials and Methods}

Ethical clearance for this study was obtained from Stellenbosch University Animal Care and Use Committee (Ethical clearance number SU-ACUD16-00094).

The growth trial was carried out from April to May 2017 on Mariendahl Experimental Farm, outside

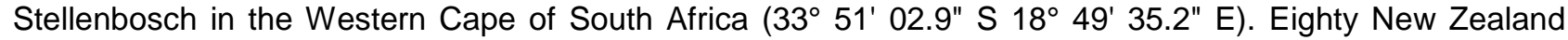
White (NZW) rabbits and 40 Phendula rabbits of both sexes were used for the trial, with 44 male and 36 female NZW, and 22 male and 18 female Phendula. The rabbits were all weaned on the same day, at $35.6 \pm$ 0.17 days old (variation in age owing to the use of natural mating), and were transferred to cages in a grower house. They were kept in same-sex groups of three, with two NZW and one Phendula per cage, and the sexes were distributed evenly throughout the house. Cages were constructed of welded wire mesh, and were $60 \times 60 \mathrm{~cm}$ and $50 \mathrm{~cm}$ high, standing $1.5 \mathrm{~m}$ off the ground. Each cage was provided with a rest mat and piece of dry pear wood to provide environmental enrichment, and wood shavings were spread beneath the cages to absorb urine. A daily lighting period of 10 hours was used, and water and a balanced pelleted diet (Table 1) were available ad libitum.

The recording of live weight started after an adaptation period of one week, with the individually marked rabbits being weighed each week for six weeks. These live weights were used to calculate the ADG for each rabbit per week. The minimum, maximum and average daily temperatures during the trial were 18.3 ${ }^{\circ} \mathrm{C}, 23.4^{\circ} \mathrm{C}$ and $20.6{ }^{\circ} \mathrm{C}$, respectively.

The rabbits were slaughtered at approximately 11 weeks old (77.6 \pm 0.17 days) at a commercial abattoir about $16 \mathrm{~km}$ from the experimental farm. Carcass and meat quality data was collected for 10 male rabbits and 10 females of each breed.

The rabbits were fasted for 12 hours prior to slaughter to clear the gastrointestinal tract, with slaughter weights (SW) being recorded prior to fasting. Slaughtering followed national regulations, with electrical stunning prior to exsanguination. After exsanguination, the carcasses were skinned and eviscerated to produce hot carcasses $(\mathrm{HC})$, which included the head and red offal, and were weighed directly after processing. The carcasses were then hung at $2-4{ }^{\circ} \mathrm{C}$ for 24 hours to cool and undergo rigor.

After chilling, the chilled carcass (CC) weights were recorded before the carcass was broken down as specified by Blasco \& Ouhayoun (1996). The head and red offal (liver, kidney, thymus, trachea, oesophagus, lungs and heart) were removed to produce the reference carcass (RC), and the removed organs and carcasses were weighed. After the removal and weighing of the dissectible fat (interscapular, inguinal and perirenal deposits), the carcasses were divided into the anatomical joints (the fore, intermediate and hind parts) as specified by Blasco \& Ouhayoun (1996). This entailed making cuts between the last thoracic and first lumbar vertebra, and between the sixth and seventh lumbar vertebrae. After weighing the portions, the hind legs were removed from the hind part and one hind leg per rabbit was dissected to provide the meat to bone ratio.

The carcass drip loss was calculated as the loss of weight during chilling, expressed as a percentage of the $\mathrm{HC}$ weight. The $\mathrm{CC}$ weight was expressed as a percentage of the SW to provide the dressing-out percentage, and the RC weight was expressed as a percentage of the CC weight to provide the RC yield. The components of the $\mathrm{CC}$ (head and red offal) were expressed as a percentage of the CC weight, whereas the dissectible fat and the portion masses were expressed as percentages of the RC weight.

The left Longissimus thoracis et lumborum (LTL) muscle was used to measure the $\mathrm{pH}$ and $\mathrm{L}^{*} \mathrm{a}^{*} \mathrm{~b}^{*}$ colour values, and to determine the cooking loss and Warner-Bratzler shear force (WBSF). The pH of the muscle was measured using a Crison PH25 portable pH meter (Lasec SA, Cape Town, South Africa). Meat colour was measured at three locations along the dorsal surface of the left LTL from the intermediate part, with a colour-guide $45^{\circ} / 0^{\circ}$ colorimeter (11 mm aperture, illuminant/observer of D65/10 ; catalogue number 6801; BYK-Gardner, Geretsried, Germany). Results were reported as L* (lightness), $a^{*}$ (redness), and b* (yellowness) values. 
Table 1 Ingredients and chemical composition of rabbit grower diet $(\mathrm{g} / \mathrm{kg})$

\begin{tabular}{|c|c|}
\hline Ingredients & $\mathrm{g} / \mathrm{kg}$ \\
\hline Alfalfa & 362 \\
\hline Wheat bran & 356 \\
\hline Sunflower meal & 126 \\
\hline Wheat & 50.0 \\
\hline Molasses & 50.0 \\
\hline Soya hulls & 31.0 \\
\hline Soybean oil & 11.0 \\
\hline Vitamin and mineral premix* & 5.00 \\
\hline Limestone & 3.70 \\
\hline Mono dicalcium phosphate $21 \%$ & 2.10 \\
\hline L-Lysine & 1.40 \\
\hline Salt & 1.00 \\
\hline DL-Methionine & 0.80 \\
\hline Robenidine $\mathrm{HCl}$ & 0.033 \\
\hline Chemical composition & $g / k g$ \\
\hline Dry matter & 892.1 \\
\hline Crude protein & 188.4 \\
\hline Ether extract & 40.6 \\
\hline Ash & 70.6 \\
\hline Crude fibre & 170.4 \\
\hline Neutral detergent fibre & 334.8 \\
\hline Acid detergent fibre & 185.3 \\
\hline Acid detergent lignin & 95.1 \\
\hline
\end{tabular}

Once the $\mathrm{pH}$ and colour had been measured, the left LTL was vacuum packed and cooked for one hour at $80{ }^{\circ} \mathrm{C}$ in a water bath, after which it was chilled at $2-4{ }^{\circ} \mathrm{C}$ overnight. After chilling, the cooked meat portions were patted dry and weighed to determine the cooking loss (Honikel, 1998). The cooked LTL muscles were used to determine the WBSF (Honikel, 1998). This entailed cutting the cooked muscle into 2$\mathrm{cm}$ thick steaks, from which $1 \times 1 \times 2 \mathrm{~cm}$ rectangular blocks were cut, with the length of the block being parallel to the muscle fibres. These blocks were then sheared perpendicularly to their long axis, with the maximum shear force required being measured with an Instron 3343 (serial number J8415, Advanced Lab Solutions, Randburg, South Africa) fitted with a 1-mm thick Warner-Bratzler blade with a semi-circular cutting edge (radius $0.508 \mathrm{~mm}$ ). The Instron had a load cell of $5 \mathrm{kN}$ and crosshead speed of $200 \mathrm{~mm} / \mathrm{min}$. The maximum load in Newton (N) was reported, with the average of the values for all blocks (five to six) being reported as the WBSF of the sample.

The right LTL that was excised from the fore part was used to determine the drip loss. It was weighed and suspended inside an inflated plastic bag at $2-4{ }^{\circ} \mathrm{C}$ for 24 hours, with care being taken that the muscle did not touch the inside of the bag. At the end of the 24-hour period the muscle was removed from the bag, blotted dry and weighed, with the drip loss being calculated as the difference between the weight before and after hanging, as a percentage of the starting weight.

The right LTL, which was excised from the intermediate part, was vacuum packed and frozen at -20 ${ }^{\circ} \mathrm{C}$ to determine proximate composition. Prior to analysis, the muscle was thawed at $2-4{ }^{\circ} \mathrm{C}$ for 24 hours and homogenized in order to remove the effects of any variation within the muscle. The moisture, ash and protein 
contents were quantified according to Association of Official Analytical Chemists (AOAC, 2002), methods 934.01, 942.05 and 992.15, respectively. The fat content was determined using the rapid solvent extraction method as described by Lee et al. (1996), with a 1:2 chloroform/methanol solution being used owing to the low fat content of rabbit loin muscle (Dalle Zotte \& Szendrö, 2011).

The growth trial was structured as a three-factor factorial experiment in a completely randomized design, with the main effects being breed, sex and age. Only the first two main effects were relevant for the carcass and meat quality data. The individual rabbits served as the experimental units, with the number of replicates varying among the treatment groups.

Statistical analysis was performed using Statistica version 13 software. Normality was tested using normal probability plots and, where necessary, outliers were removed and the Box-Cox transformation was used to normalize the data prior to statistical analysis. This was necessary only for the hindleg meat to bone ratio data. Statistica's variance, estimation, precision and comparison (VEPAC) mixed-model function was used to determine the significance of the main effects and second- and third-order interactions for the live performance data, and the R Im package was used for the carcass and meat quality data. Initial weight (live weight at six weeks old) was used as a covariate for the analyses. Fisher's LSD test was used to identify differences between the treatment combinations, with the adjusted least squares means being used for post hoc calculations.

Main effects and interactions with $P \leq 0.05$ were considered significant, and values are reported as least squares means \pm standard error (SE).

\section{Results}

Only the sex-age interaction was significant for the live performance data (Figure 1), with females having greater live weights than males at 11 weeks old $(P<0.001)$. This was as a result of a continued decline in the ADG of males, but not of females from 9 to 11 weeks old $(P=0.04)$.

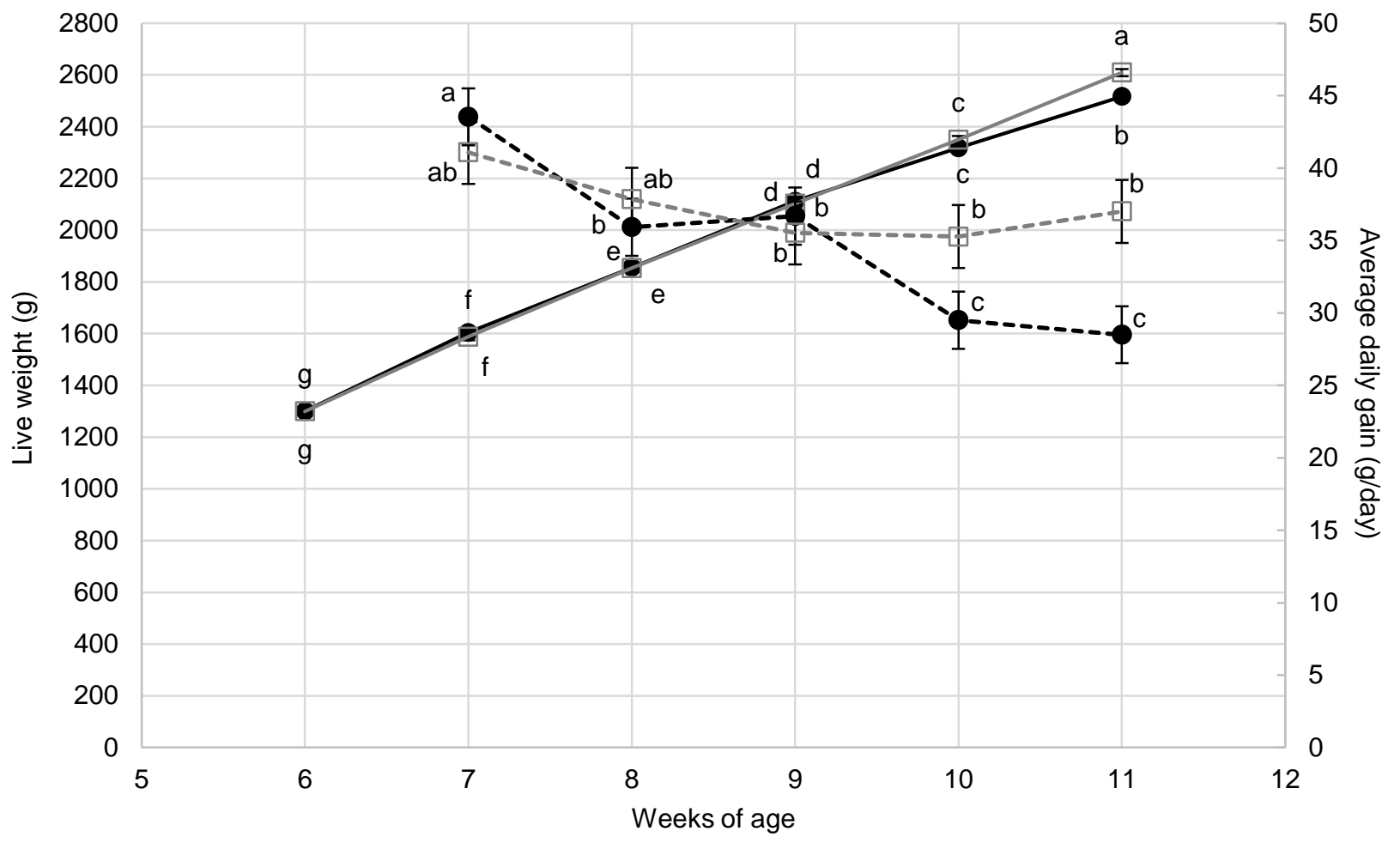

$\longrightarrow$ Male live weight $\quad \square$ Female live weight $\quad$--๑-- Male ADG $\quad--\square--$ Female ADG

Figure 1 Live weight and average daily gain from 6 to 11 weeks old of male and female New Zealand White and Phendula rabbits

Because there were no differences between breeds, they were pooled per sex. Significant differences $(P \leq 0.05)$ between the sexes are indicated by the significance letters adjacent to the data points and error bars show the standard errors of the means.

There were no effects of breed or sex on the SW, HC weight or CC weight (Table 2). However, there was a significant breed-sex interaction $(P=0.02)$ for carcass drip loss, with NZW females $\left(4.99^{\mathrm{a}} \pm 0.218 \%\right)$ 
losing significantly more weight during cooling than NZW males $\left(4.14^{\mathrm{b}} \pm 0.190 \%\right)$, but Phendula females $\left(4.06^{\mathrm{b}} \pm 0.287 \%\right)$ lost less weight than Phendula males $\left(4.45^{\mathrm{ab}} \pm 0.288 \%\right)$.

Sex had a significant effect on the dressing-out percentage $(P=0.004)$, with males retaining a larger percentage of their live weight in the chilled carcass than females (Table 2). The RC weight did not show any significant treatment effects. However, the RC yield differed between the breeds $(P=0.05)$ and sexes $(P$ $=0.02$ ), with NZW having greater yields than Phendula, and females having greater yields than males.

Table 2 Effects of breed and sex on the carcass traits of New Zealand White and Phendula meat rabbits (least squares means \pm SE)

\begin{tabular}{|c|c|c|c|c|c|}
\hline & \multirow{2}{*}{ Overall } & \multicolumn{2}{|c|}{ Breed } & \multicolumn{2}{|c|}{ Sex } \\
\hline & & NZW & Phendula & Male & Female \\
\hline Slaughter weight (kg) & $2.62 \pm 0.034$ & $2.63 \pm 0.043$ & $2.60 \pm 0.054$ & $2.60 \pm 0.051$ & $2.63 \pm 0.046$ \\
\hline Hot carcass weight $(\mathrm{kg})$ & $1.55 \pm 0.022$ & $1.54 \pm 0.029$ & $1.55 \pm 0.035$ & $1.56 \pm 0.033$ & $1.54 \pm 0.032$ \\
\hline $\begin{array}{l}\text { Chilled carcass }(\mathrm{CC}) \\
\text { weight }(\mathrm{kg})\end{array}$ & $1.48 \pm 0.021$ & $1.47 \pm 0.028$ & $1.48 \pm 0.033$ & $1.49 \pm 0.032$ & $1.47 \pm 0.029$ \\
\hline Carcass drip loss (\%) & $4.41 \pm 0.131$ & $4.56 \pm 0.167$ & $4.26 \pm 0.202$ & $4.29 \pm 0.166$ & $4.52 \pm 0.202$ \\
\hline $\begin{array}{l}\text { Dressing-out percentage } \\
(\%)\end{array}$ & $56.3 \pm 0.28$ & $56.0 \pm 0.39$ & $56.7 \pm 0.41$ & $57.1^{a} \pm 0.42$ & $55.6^{b} \pm 0.31$ \\
\hline $\begin{array}{l}\text { Reference carcass (RC) } \\
\text { weight }(\mathrm{kg})\end{array}$ & $1.26 \pm 0.019$ & $1.26 \pm 0.024$ & $1.25 \pm 0.031$ & $1.26 \pm 0.029$ & $1.25 \pm 0.026$ \\
\hline RC yield (\% CC) & $85.1 \pm 0.14$ & $85.3^{\mathrm{a}} \pm 0.14$ & $84.9^{b} \pm 0.24$ & $84.8^{b} \pm 0.22$ & $85.4^{a} \pm 0.16$ \\
\hline Head (g) & $111.3 \pm 1.53$ & $111.5 \pm 2.11$ & $111.1 \pm 2.26$ & $113.6^{a} \pm 2.33$ & $109.0^{b} \pm 1.94$ \\
\hline Head (\% CC) & $7.56 \pm 0.064$ & $7.58 \pm 0.098$ & $7.54 \pm 0.084$ & $7.65 \pm 0.066$ & $7.46 \pm 0.107$ \\
\hline Red offal (g) & $105.3 \pm 2.35$ & $103.0 \pm 2.68$ & $107.7 \pm 3.87$ & $110.3^{a} \pm 2.60$ & $100.4^{b} \pm 3.68$ \\
\hline Red offal (\% CC) & $7.15 \pm 0.152$ & $6.98 \pm 0.106$ & $7.33 \pm 0.284$ & $7.47^{a} \pm 0.208$ & $6.84^{b} \pm 0.203$ \\
\hline Dissectible fat (g) & $54.7 \pm 3.54$ & $49.2 \pm 5.01$ & $60.2 \pm 4.86$ & $52.0 \pm 3.90$ & $57.4 \pm 5.95$ \\
\hline Dissectible fat (\% RC) & $4.36 \pm 0.287$ & $3.87 \pm 0.349$ & $4.85 \pm 0.438$ & $4.21 \pm 0.391$ & $4.51 \pm 0.427$ \\
\hline Fore part (kg) & $0.479 \pm 0.0075$ & $0.486 \pm 0.0098$ & $0.472 \pm 0.0112$ & $0.487^{a} \pm 0.0119$ & $0.471^{b} \pm 0.0092$ \\
\hline Fore part (\% RC) & $38.1 \pm 0.20$ & $38.6^{a} \pm 0.26$ & $37.6^{\mathrm{b}} \pm 0.28$ & $38.6^{a} \pm 0.25$ & $37.6^{b} \pm 0.28$ \\
\hline Intermediate part (kg) & $0.252 \pm 0.0050$ & $0.247 \pm 0.0052$ & $0.257 \pm 0.0086$ & $0.254 \pm 0.0071$ & $0.251 \pm 0.0071$ \\
\hline Intermediate part (\% RC) & $20.0 \pm 0.17$ & $19.6^{b} \pm 0.16$ & $20.4^{a} \pm 0.28$ & $20.1 \pm 0.21$ & $20.0 \pm 0.28$ \\
\hline Hind part (kg) & $0.471 \pm 0.0071$ & $0.477 \pm 0.0074$ & $0.466 \pm 0.0122$ & $0.470 \pm 0.0116$ & $0.473 \pm 0.0086$ \\
\hline Hind part (\% RC) & $37.6 \pm 0.26$ & $37.9 \pm 0.33$ & $37.2 \pm 0.38$ & $37.2 \pm 0.34$ & $37.9 \pm 0.38$ \\
\hline Hindleg meat: bone ratio & $5.94 \pm 0.182$ & $5.98 \pm 0.315$ & $5.89 \pm 0.191$ & $5.90 \pm 0.212$ & $5.98 \pm 0.302$ \\
\hline
\end{tabular}

NZW: New Zealand White; SE: standard error; red offal: liver, kidney, thymus, trachea, oesophagus, lungs and heart

${ }^{a b}$ Means with different superscript letters in the same row (within main effect) differ significantly $(P \leq 0.05)$

The components of the chilled carcass (Table 2), namely the head and red offal, differed between the sexes, with males having heavier heads $(P=0.03)$ and heavier red offal $(P=0.02)$. The proportion of the red offal as a percentage of the CC weight was also greater for males $(P=0.03)$.

There were no differences in the weights or proportions of the dissectible fat. However, the proportion of the fore part and intermediate part differed between the breeds, and the proportion and weight of the fore part differed between the sexes (Table 2). NZW carcasses had a greater proportion in the fore part $(P=0.01)$ and smaller proportion in the intermediate part $(P=0.01)$ than Phendula carcasses, and male rabbits had heavier $(P=0.05)$ and greater proportions $(P=0.01)$ of the fore part than female rabbits. There were no differences between the breeds or sexes in the proportion of the hind part. However, the breed-sex interaction was significant for the hindleg meat to bone ratio $(P=0.03)$. NZW males $\left(6.31^{\mathrm{a}} \pm 0.305\right)$ had significantly greater meat to bone ratios than Phendula males $\left(5.49^{\mathrm{b}} \pm 0.222\right)$, while the female rabbits had intermediate values that did not differ between the breeds (NZW: $5.66^{\mathrm{ab}} \pm 0.545$, Phendula: $6.30^{\mathrm{ab}} \pm 0.242$ ).

There were no significant differences between the breeds or sexes for the physical or chemical meat quality data (Table 3 ). 
Table 3 Effects of breed and sex on the physical and proximate chemical meat quality of the Longissimus thoracis et lumborum muscle of New Zealand White and Phendula meat rabbits (least squares means \pm SE)

\begin{tabular}{|c|c|c|c|c|c|c|}
\hline & & \multirow{2}{*}{ Overall } & \multicolumn{2}{|c|}{ Breed } & \multicolumn{2}{|c|}{ Sex } \\
\hline & & & NZW & Phendula & Male & Female \\
\hline \multicolumn{2}{|c|}{ Drip loss (\%) } & $0.94 \pm 0.042$ & $0.96 \pm 0.060$ & $0.91 \pm 0.059$ & $0.90 \pm 0.045$ & $0.97 \pm 0.071$ \\
\hline \multicolumn{2}{|c|}{ Cooking loss (\%) } & $25.17 \pm 0.266$ & $25.49 \pm 0.249$ & $24.85 \pm 0.466$ & $25.12 \pm 0.411$ & $25.22 \pm 0.348$ \\
\hline \multicolumn{2}{|l|}{$\mathrm{pH}$} & $5.95 \pm 0.023$ & $5.97 \pm 0.032$ & $5.94 \pm 0.035$ & $5.94 \pm 0.028$ & $5.97 \pm 0.037$ \\
\hline & $L^{*}$ & $52.95 \pm 0.380$ & $53.08 \pm 0.534$ & $52.83 \pm 0.552$ & $53.10 \pm 0.471$ & $52.80 \pm 0.606$ \\
\hline \multirow[t]{2}{*}{ Colour: } & $a^{*}$ & $-0.72 \pm 0.167$ & $-0.69 \pm 0.245$ & $-0.75 \pm 0.231$ & $-0.53 \pm 0.248$ & $-0.91 \pm 0.222$ \\
\hline & $b^{*}$ & $7.56 \pm 0.246$ & $7.34 \pm 0.377$ & $7.78 \pm 0.319$ & $7.57 \pm 0.327$ & $7.55 \pm 0.377$ \\
\hline \multicolumn{2}{|c|}{ Warner-Bratzler shear force $(\mathrm{N})$} & $26.66 \pm 0.864$ & $27.19 \pm 1.248$ & $26.12 \pm 1.220$ & $26.73 \pm 1.212$ & $26.58 \pm 1.263$ \\
\hline \multicolumn{2}{|c|}{ Moisture (\%) } & $73.58 \pm 0.118$ & $73.50 \pm 0.177$ & $73.66 \pm 0.158$ & $73.58 \pm 0.166$ & $73.57 \pm 0.171$ \\
\hline \multicolumn{2}{|c|}{ Protein (\%) } & $22.81 \pm 0.145$ & $22.75 \pm 0.254$ & $22.87 \pm 0.146$ & $22.76 \pm 0.202$ & $22.86 \pm 0.212$ \\
\hline \multicolumn{2}{|c|}{ Lipids (\%) } & $2.56 \pm 0.115$ & $2.71 \pm 0.165$ & $2.42 \pm 0.156$ & $2.71 \pm 0.162$ & $2.42 \pm 0.161$ \\
\hline \multicolumn{2}{|c|}{ Ash (\%) } & $1.27 \pm 0.018$ & $1.28 \pm 0.030$ & $1.27 \pm 0.020$ & $1.27 \pm 0.028$ & $1.27 \pm 0.022$ \\
\hline
\end{tabular}

\section{Discussion}

Overall, the live weights of both the South African NZW and Phendula rabbits compared well with those reported for various breeds, breed crosses and hybrid lines in recent literature (Pascual et al., 2015; Alabiso et al., 2017; Nasr et al., 2017; Belabbas et al., 2019). However, in the absence of standardized rearing and environmental conditions, the value of these comparisons is limited. Furthermore, additional studies that provide feed intake and efficiency data are necessary to produce a more complete picture of the efficiency of growth of these breeds, particularly when one considers the results of North et al. (2018a), which suggested that the feed efficiency of NZW growers in a similar system was less than desirable.

The greater live weights for female rabbits than males of both breeds at 11 weeks old resulted from the greater ADG of females towards the end of the growth period (Figure 1), These results differed from North et al. (2018a), in which no sex effect on live weight was detected for NZW from the same genetic stock. Bernardini Battaglini et al. (1995), Ortiz Hernández \& Rubio Lozano (2001), Yalçin et al. (2006) and Alabiso et al. (2017) similarly reported no sex differences in live weight or SW for a variety of genetic types. However, whereas Blasco \& Gomez (1993) found no sex differences in a line selected for growth rate, females from a line selected for litter size had significantly greater live weights than males from the same line. Because it is generally accepted that adult female rabbits are heavier than their male counterparts (Blasco \& Gomez, 1993), the results of this study may suggest that this dimorphism is particularly distinct in South African NZW and Phendula rabbits, and that these breeds mature relatively early.

in terms of the differences between the sexes in live weight at the end of the growth period, the lack of a significant effect of sex on SW was unexpected. However, power of the test was more limited for this effect owing to the smaller sample size used for carcass traits compared with traits that were measured on the live rabbits. Nonetheless, the lack of an effect of breed or sex on the HC and CC weights was not surprising.

In contrast, the breed-sex interaction for carcass drip loss was significant, with female NZW losing more carcass weight during chilling than males, but the sexes did not differ for the Phendula. This difference between the breeds was not without precedent, as Bernardini Battaglini et al. (1995), Ortiz Hernández \& Rubio Lozano (2001), and Alabiso et al. (2017) all reported effects of genetic type on carcass drip loss. However, only Alabiso et al. (2017) reported that female carcasses had greater losses during chilling than males. Because a factor that affects carcass drip loss is the degree of fat cover of the carcass, the lack of concomitant differences in the dissectible fat content was surprising, and suggested that other carcass traits may have played a role.

The greater dressing-out percentage for males than females concurred with some previous studies (Alabiso et al., 2017), but not others, with Bernardini Battaglini et al. (1995), Ortiz Hernández \& Rubio Lozano (2001), and Yalçin et al. (2006) reporting no significant sex-differences in carcass yields. However, Trocino et al. (2003) reported greater dressing percentages in males than females, and concluded that this 
was owing to the greater proportion of gut content in females. Overall, the dressing-out percentages in this study appeared to fall within the normal range for rabbits (Dalle Zotte, 2002).

Despite the greater dressing-out percentage for males, females had greater RC yields, with this probably being due to their lighter heads and red offal (Table 2). The heavier heads in the male NZW and Phendula were not surprising, as this aligns with the breed standards (Steenekamp, 2014), and concurs with the findings of Bernardini Battaglini et al. (1995), Alabiso et al. (2017), and North et al. (2018b). Because the liver, kidney, thymus, trachea, oesophagus, lungs, and heart were weighed together, no conclusions could be drawn from the greater proportion of these components in male rabbits.

The RC yield also differed between the breeds, with NZW having greater RC yields than Phendula. Because neither the head nor red offal differed significantly in weight or proportion between the breeds, it is difficult to explain this difference. Breed also had a significant effect on the proportions of the carcass portions, specifically the fore and intermediate parts, with the NZW having a larger proportion of the lowervalue fore part, and less of the higher-value intermediate part. These differences may reflect dissimilarities in body structure between the breeds, and in emphasis placed during breeding, as breed effects on carcass traits are well documented (Ouyed \& Brun, 2008).

The weight and proportion of the fore part also differed between the sexes, with males having heavier fore parts than females. This concurred with the findings of Alabiso et al. (2017), and was probably because of the effects of sex on the growth and development of different parts of the body, with males typically showing greater development in the neck and thorax (Lawrie \& Ledward, 2006).

Overall, the proportion of the high-value intermediate part in both breeds and sexes seemed low relative to results reported in previous studies, which generally appeared to suggest a similar yield for the intermediate and fore parts of the carcass (Szendrö et al., 1998; Ouyed \& Brun, 2008). However, this probably just reflects differences in the division of the carcasses between studies, as portioning methods appear to vary, despite the standardized guidelines provided by Blasco and Ouhayoun (1996). This is supported by the more similar proportions of similarly defined portions reported by Daszkiewicz et al. (2012), Alabiso et al. (2017), and Belabbas et al. (2019).

The significant breed-sex interaction found for the hindleg meat: bone ratio seemed to suggest a greater ratio in NZW males than Phendula males, but no significant breed effect in females. This could be linked to differences in the breed specifications and selection criteria for the males of each breed. Effects of the sire strain on the hindleg meat yield have been reported (Bernardini Battaglini et al., 1995). Overall, the hindleg meat to bone ratio appeared to be towards the upper end of previous ranges reported for rabbits, suggesting relatively good yields (Dalle Zotte, 2002).

There were no significant effects of breed or sex on the physical or proximate chemical meat quality traits. However, because of the lack of information about South African rabbit breeds, it is worth briefly discussing the results from the current study in comparison with values reported in recent literature.

The comparison of the basic physical meat quality parameters of the loin meat with those in the literature was complicated by the variety of processing and measurement methods. Nonetheless, the cooking loss appeared to be slightly low relative to results for studies that used similar methodology (Combes et al., 2008; Simitzis et al., 2014; Koné et al., 2016), probably because of the comparatively high pH values (Combes et al., 2008; Simitzis et al., 2014; Alabiso et al., 2017; North et al., 2018b; Belabbas et al., 2019). This high $\mathrm{pH}$ may have been linked to fasting the rabbits prior to slaughter, in addition to the stress of transporting them to the abattoir (Dalle Zotte, 2002).

The high $\mathrm{pH}$ was probably also linked to the low $\mathrm{L}^{*}$, very low $\mathrm{a}^{*}$, and high $\mathrm{b}^{*}$ values, relative to other studies (Combes et al., 2008; Maj et al., 2012), although the values were similar to those reported by North et al. (2018b). However, numerous other structural and biochemical traits that manifest in muscle may change meat colour, and these can be influenced by a variety of factors, such as genetic type and postmortem temperature variation (Maj et al., 2012). Shear force values reported in the literature vary widely, and have been measured with a variety of methods. However, the average WBSF in this study appeared to fall within the lower end of the range of results (Castellini et al., 1998; Pla et al., 1998; Pla, 2008; Simitzis et al., 2014; North et al., 2018b), suggesting that the meat was relatively tender.

Regarding the nutritional value of the meat, as assessed by the proximate chemical composition, the moisture, protein and ash contents appeared to be consistent with the values reported by Dalle Zotte \& Szendrö (2011). However, the lipid content of the loin, while within the reported range, was greater than might be anticipated, based on previous results. This aligned with the observed dissectible fat content, as a percentage of the RC, relative to previous studies (Pla et al., 1998; Trocino et al., 2003; Alabiso et al., 2017), and could be linked to the apparent maturity of the rabbits at slaughter, as indicated by their slaughter weight (Dalle Zotte, 2002) and the significant effects of sex on live weight.

The apparent maturity of the South African breeds in this study may be due to the intense selection for growth that has been carried out on commercial breeds and hybrid lines in other countries, as such selection 
can reduce maturity at the same slaughter weight (Pla et al., 1998). While early maturation tends to improve carcass yields, it can detrimentally increase the carcass and meat fat content, as was seen in this study, and decrease feed efficiency (Dalle Zotte, 2002). However, further research would be necessary to confirm these comparisons.

\section{Conclusion}

The growth and meat quality of NZW and Phendula rabbits appeared to be similar under the conditions used in this study, with the only difference being the slightly more favourable conformation of the carcasses from the Phendula rabbits, which had a greater proportion of the high-value intermediate part. Further research to compare the two breeds under extensive or more environmentally challenging conditions would be interesting as the Phendula landrace was originally developed for use under such conditions. Such studies should include measurement of feed intake to facilitate comparisons of feed efficiency, The overall comparison of the results of this study with recent literature suggested that the growth, carcass and meat quality conformed largely to expectations. However, the significant differences between the sexes for several traits, including live weight and average daily gain, in conjunction with the relatively high carcass and meat fat content, suggested that the rabbits matured at a relatively young age. This could be detrimental to feed efficiency and meat quality from a health perspective, and may suggest that a younger slaughter age may be preferable.

\section{Acknowledgements}

The authors would like to thank Prof Martin Kidd from the Centre for Statistical Consultation at Stellenbosch University for performing the statistical analysis of the data. The sampling and laboratory assistance provided by the staff and students of the Animal, Food Science and Biochemistry Departments of Stellenbosch University was also invaluable. This work is based on research supported by the South African Research Chairs Initiative of the Department of Science and Technology and the National Research Foundation of South Africa (UID: 84633), and partly by the Department of Trade and Industry's THRIP program (THRIP/64/19/04/2017). Any opinions, findings and conclusions or recommendations expressed in this material are those of the author(s) and the National Research Foundation does not accept any liability in this regard.

\section{Authors' Contributions}

All authors participated in the planning of the experiments and writing and reviewing of the manuscript. MKN was responsible for running the trial, performing laboratory analysis and data processing and interpretation.

\section{Conflict of Interest Declaration}

There are no conflicts of interest.

\section{References}

Abu, O.A., Onifade, A.A., Abanikannda, O.T.F. \& Obiyan, R.I., 2008. Status and promotional strategies for rabbit production in Nigeria. Proc. 9th World Rabbit Cong., Verona, Italy, 10-13 June 2008, pp. 1499-1504

Alabiso, M., Di Grigoli, A., Mazza, F., Maniaci, G., Vitale, F. \& Bonanno, A., 2017. A 3-week feed restriction after weaning as an alternative to a medicated diet: effects on growth, health, carcass and meat traits of rabbits of two genotypes. Animal 11(9), 1608-1616.

Belabbas, R., de la Luz García, M., Ainbaziz, H., Benali, N., Berbar, A., Boumahdi, Z. \& Argente, M.J., 2019. Growth performances, carcass traits, meat quality, and blood metabolic parameters in rabbits of local Algerian population and synthetic line. Vet. World 12, 55-62.

Bernardini Battaglini, M., Castellini, C. \& Lattaioli, P., 1995. Effect of sire strain, feeding, age and sex on rabbit carcass. World Rabbit Sci. 3(1), 9-14.

Blasco, A. \& Gómez, E., 1993. A note on growth curves of rabbit lines selected on growth rate or litter size. Anim. Prod. $57,332-334$.

Blasco, A. \& Ouhayoun, J., 1996. Harmonization of criteria and terminology in rabbit meat research. Revised proposal. World Rabbit Sci. 4(2), 93-99.

CABI, 2019a. Rabbit hemorrhagic disease virus. In: Invasive species compendium. CAB International, Wallingford, UK. https://www.cabi.org/ISC/datasheet/96420

$\mathrm{CABI}, 2019 \mathrm{~b}$. Myxomatosis. In: Invasive species compendium. CAB International, Wallingford, UK. https://www.cabi.org/ISC/datasheet/73879

Castellini, C., Dal Bosco, A., Bernardini, M. \& Cyril, H.W., 1998. Effect of dietary vitamin E on the oxidative stability of raw and cooked rabbit meat. Meat Sci. 50(2), 153-161.

Combes, S., Gonzalez, I., Dejean, S., Baccini, A., Jehl, N., ..., Larzul, C., 2008. Relationships between sensory and physicochemical measurements in meat of rabbit from three different breeding systems using canonical correlation analysis. Meat Sci. 80, 835-841.

Dalle Zotte, A., 2002. Perception of rabbit meat quality and major factors influencing the rabbit carcass and meat quality. Livest. Prod. Sci. 75, 11-32.

Dalle Zotte, A. \& Szendrō, Z., 2011. The role of rabbit meat as functional food. Meat Sci. 88, 319-331. 
Daszkiewicz, T., Gugolek, A., Janiszewski, P., Kubiak, D. \& Czoik, M., 2012. The effect of intensive and extensive production systems on carcass quality in New Zealand White rabbits. World Rabbit Sci. 20, 25-32.

Finzi, A., 2000. Raising rabbits for food security. Proc. 7th World Rabbit Cong., Valencia, Spain, volume B., 4-7 July 2000, pp. 13-38.

Gauteng Smallholder, 2014. SA Phendula: New meat rabbit breed. Gauteng Smallholder, October 2014, 8-13. Available from: http://grba.org.za/sa-phendula. Accessed: 20 May 2019.

Hoffman, L., Nkhabutlane, P., Schutte, D.W. \& Vosloo, C., 2004. Factors affecting the purchasing of rabbit meat: A study of ethnic groups in the Western Cape. J. Fam. Ecol. Consum. Sci. 32(1), 26-35.

Hoffman, L.C., Vosloo, C., Nkhabutlane, P. \& Schutte, D.W., 2005. Associations with rabbits and rabbit meat of three different ethnic groups in Stellenbosch, South Africa. J. Fam. Ecol. Consum. Sci. 33, 63-72.

Honikel, K.O., 1998. Reference methods for the assessment of physical characteristics of meat. Meat Sci. 49(4), 447457.

Koné, A.P., Cinq-Mars, D., Desjardins, Y., Guay, F., Gosselin, A. \& Saucier, L., 2016. Effects of plant extracts and essential oils as feed supplements on the quality and microbial traits of rabbit meat. World rabbit Sci. 24, 107-119.

Lawrie, R.A. \& Ledward, D.A., 2006. Lawrie's meat science (7th ed.). Woodhead, Cambridge, England.

Lebas, F., Coudert, P., de Rochambeau, H. \& Thébault, R., 1997. The rabbit - husbandry, health and production (revised). Food and Agricultural Organization of the United Nations, Rome, Italy.

Lee, C.M., Trevino, B. \& Chaiyawat, M., 1996. A simple and rapid solvent extraction method for determining total lipids in fish tissue. J. AOAC Int. 79(2).

Lukefahr, S.D., 2007. Strategies for the development of small- and medium-scale rabbit farming in South-East Asia. Livest. Res. Rural Dev. 19(9), 1-12.

Maj, D., Bieniek, J., Sternstein, I., Wȩglarz, A. \& Zapletal, P., 2012. Effect of genotype and sex on meat colour changes in rabbit. Arch. Tierzucht 55(4), 385-390.

Nasr, M.A.F., Abd-Elhamid, T. \& Hussein, M.A., 2017. Growth performance, carcass characteristics, meat quality and muscle amino-acid profile of different rabbits breeds and their crosses. Meat Sci. 134, 150-157.

North, M.K., Nkhabutlane, P. \& Hoffman, L.C., 2017. The effect of age on the carcass composition, portion yield and proximate composition of two rabbit genetic types in South Africa. World Rabbit Sci. 25, 281- 288.

North, M.K., Dalle Zotte, A. \& Hoffman, L.C., 2018a. Effect of quercetin supplementation on the growth, feed efficiency and serum hormone levels of New Zealand White rabbits. S. Afr. J. Anim. Sci. 48(6), 1128-1139.

North, M.K., Dalle Zotte, A. \& Hoffman, L.C., 2018b. The effects of quercetin supplementation on New Zealand White grower rabbit carcass and meat quality - A short communication. Meat Sci. 145, 363-366.

Ortiz Hernández, J.A. \& Rubio Lozano, M.S., 2001. Effect of breed and sex on rabbit carcass yield and meat quality. World Rabbit Sci. 9(2), 51-56.

Ouyed, A. \& Brun, J., 2008. Heterosis, direct and maternal additive effects on rabbit growth and carcass characteristics. Proc. 9th World Rabbit Cong., Verona, Italy,10-13 June 2008, pp. 10-13.

Pascual, M., Calle, E.W. \& Blasco, A., 2015. Comparison of degrees of maturity of rabbit lines selected for different traits. World Rabbit Sci. 23, 155-161.

Pla, M., 2008. A comparison of the carcass traits and meat quality of conventionally and organically produced rabbits. Livest. Sci. 115, 1-12.

Pla, M., Guerrero, L., Guardia, D., Oliver, M. A. \& Blasco, A., 1998. Carcass characteristics and meat quality of rabbit lines selected for different objectives: I. Between lines comparison. Livest. Prod. Sci. 54, 115-123.

Simitzis, P.E., Babaliaris, C., Charismiadou, M.A., Papadomichelakis, G., Goliomytis, M., Symeon, G.K. \& Deligeorgis, S.G., 2014. Effect of hesperidin dietary supplementation on growth performance, carcass traits and meat quality of rabbits. World Rabbit Sci. 22, 113-121.

Steenekamp, K., 2014. Rabbits: The South African all breeds standards of excellence. South African Rabbit Judges Council, Cape Town, South Africa.

Szendrő, Z. \& Dalle Zotte, A., 2011. Effect of housing conditions on production and behaviour of growing meat rabbits: A review. Livest. Sci. 137, 296-303.

Szendrő, Z., Radnai, I., Biró-Németh, E., Romvári, R., Milisits, G. \& Kenessey, Á., 1998. The effect of live weight on the carcass traits and the chemical composition of meat of Pannon white rabbits between 2.2 and $3.5 \mathrm{~kg}$. World Rabbit Sci. 6(2), 243-249.

Trocino, A., Xiccato, G., Queaque, P.I. \& Sartori, A., 2003. Effect of transport duration and gender on rabbit carcass and meat quality. World Rabbit Sci. 11(1), 23-32.

Yalçin, S., Onbaşilar, E.E. \& Onbaşilar, I., 2006. Effect of sex on carcass and meat characteristics of New Zealand White rabbits aged 11 weeks. Asian-Aust. J. Anim. Sci. 19(8), 1212-1216. 